\title{
Developing a Usage-centered e-Payment Model using Open Network System
}

\author{
Arogundade O.T \\ Institute of System Science, \\ Academy of Mathematics and \\ System Science, Chinese \\ Academy of Science, Beijing, \\ 100190 China.
}

\author{
Ikotun A. Motunrayo \\ Department of Computer \\ Science, Yaba College of \\ Technology, Yaba - Lagos..
}

\author{
Olaniyi Ademola \\ University of Agriculture, \\ Abeokuta
}

\begin{abstract}
One-tenth of the world's ever-growing internet population shops online, representing a staggering 627 million people. As more organization adopts e-payment methods, changes in the market-place for business-to-business (B2B) payments increasingly demand executives' attention. Businesses are beginning to realize they must add new payment options to a process still dominated by paper checks, wire transfers, and automated clearinghouse $(\mathrm{ACH})$ transactions.
\end{abstract}

Extreme programming and other emerging agile methods represent an important new direction in software engineering and development. This paper explores the integration of both usage-centred engineering and extreme programming for epayment model using open network system.

This paper describes the development of a B2B E-payment system using Use-Case modelling techniques as well as, ESignatures and XML. We propose an open network system which can adapt to users changing needs as well as allowing effective and secured transaction via any customers' bank account.

Keywords: Business-to-Business payments, e-Payments, Usage-centred Model, Extreme Programming, Open System Network.

\section{INTRODUCTION}

Usage-centred is a systematic, model driven approach to improving product usability. A few simple but powerful models of user roles, tasks and interface content guide the user interface design toward a better fit with the real needs of users.

The Internet has completely changed the way most businesses operate today. E-commerce uses internetworked computers to create and transform business relationships. Web applications provide business solutions that improve the quality of goods and services, increase the speed of service delivery, and reduce the cost of business operations. However, many ventures into web application development fail because the systems are very complex and the users' requirements are continuously changing. Inefficient communication between the end user and the developer is another contributing factor. To successfully accomplish the development of a web application, one needs to visually model the system's architecture. A visual model helps in coherently grasping the changing user requirements and effectively communicates them to the development team.

Requirements analysis along with abstraction (i.e., removing unnecessary details) is critical factors in web application development. It is easier and more cost effective to correct an error at the requirement or design stage than at the implementation or maintenance stage. Traditional requirement analysis consists of identifying relevant data functions that a software system would support. The data to be handled by the system might be described in terms of entity relationship diagrams, while the functions might be described in terms of data flows. Indeed, object-oriented analysis techniques offer Class, Use-Case, State Chart, and Sequence diagrams along with other diagrammatic notations for modelling.

A method that performs requirements gathering for conceptual and navigational design of Web applications based on Scenarios, Use-Case and User Interaction Diagrams (UIDs) can also be used. Scenarios are used to validate the requirements and are automatically generated from the UseCases obtained from the users. They are also used to describe interface and navigational aspects, especially in the redesign of an existing web site.

This paper describes the development of a B2B E-commerce system exploring the integration of usage-centred engineering and agile methods (extreme programming) as well as, ESignatures and XML. Critical success factors including effective communication between users and developers, processing time, process cost, reusability, efficiency, security etc. for successfully building an E-commerce system are considered.

\section{BACKGROUND AND RELATED RESEARCH}

We developed the B2B system described in this paper using UML and usage-centred engineering for formalization of user requirements; and E-signatures for security purposes.

Models are useful for understanding problems, communicating with project team members (customers, domain experts, analysts, designers, etc.), modelling enterprises, preparing documentation, and designing programs and databases. Models promote better understanding of the requirements by filtering out nonessential details and establishing the most suitable architectural basis for design..

Usage-centred engineering is used to specify, visualize, and document the artefacts of an object-oriented system under development. Use-Case Diagrams model the user requirements and their interactions with the system at a very high level of abstraction.

In this paper, we focus on $\mathrm{B} 2 \mathrm{~B}$ e-commerce. The trend of ecommerce transactions shows that B2B transactions increased from 8 billion U.S dollars in 1997 to $\$ 183$ billion U.S dollars in 2001. In Japan, it is predicted that the amount in B2B transactions will reach $\$ 680$ billion U.S dollars in 2003, while in the USA; it should reach $\$ 1650$ billion U.S dollars. Accordingly, only companies that can manage B2B ecommerce will survive in the global mega-competition. 
Electronic Commerce (e -commerce) is the ability to perform business transactions involving the exchange of goods and services between two or more parties using electronic tools and techniques [1]. E-commerce enables companies to conduct their business from prospecting to order processing and delivery on-line [6]. Electronic invoice and payment systems offer enormous promise for cost savings, speed, and transparency in business-to-business transactions. The technology has a lot going for it: It's getting more robust all the time, and big financial services firms, including American Express and JPMorgan Chase, are partnering with payment software developers to host the systems [7].

The volume of e-payment activity has risen steadily since 1979 and shows no sign of slowing down. Motivating this trend has been consumer willingness to submit payments electronically. Increasingly, businesses have sought to improve their understanding of the value of e-payment systems. Studies have begun to illustrate in greater detail the specific value afforded and risk incurred to businesses by epayment systems. [5] discusses some methods in online business-to-business (B2B) payment. Featuring banking money-transfer technology based on automated clearing house, disadvantages of bank-specific payment systems, problems in using electronic data interchange in online payments.

Along these lines, newer e-payment technologies possess attributes (such as systems integration, remittance standards, security, and an uncertain value proposition) that promise to help overcome past obstacles. That will be done through technologies that can be implemented by a greater number of entities (lower up-front investment costs), incorporate improved data capabilities (permitting varying degrees of data remittance), and be built on existing networks (more certain return on investment). According to [2], Commercial payments expert Frank Martien of First Annapolis Consulting share new research on the B2B payments landscape, introducing new research and aggregates key studies to give a clearer picture of the B2B payments landscape which focuses on payments migration and $\mathrm{A} / \mathrm{P}$ integration trends among checks, wires, $\mathrm{ACH}$, and commercial cards, what really matters to end-user organizations today, what leading suppliers are currently saying about card acceptance, the future of card-based B2B payments and the key characteristics of winning providers and the key strategies for identifying high-risk corporate card transactions accurately and efficiently. Financial institutions and businesses must therefore evaluate their e-payment product portfolios, coordinating and comparing them against organizational needs and goals.

Those seeking to implement e-payment technologies must consider not only their emerging technology options but evolving payment needs as well. Although ACH based systems, enhanced p-cards, and open networks have different characteristics, a business may implement a combination of technologies. However, the long-term goals of an organization, from both a business and process perspective, should be analyzed and agreed upon before a new payment regime is implemented. Organizations that embrace the flexibility of open network e-payment systems will realize benefits beyond their peers that embrace traditional $\mathrm{ACH}-$ and enhanced p-card-based e-payment systems[3].

According to the ECB Issues Paper on e-payments, "the conditions applying to electronic signatures could strengthen confidence in and general acceptance of the new technologies". Hence, E-signature is essential to provide epayment services with the same level of certainty and security as face-to-face transactions and traditional electronic payments on "closed networks" [4].

Being technologically neutral, the e-signature Directive defines qualified electronic signatures in a functional but not in a technical way. Every kind of electronic authentication attached to or logically associated with the data to be signed gets legal validity: such a general authentication method is an "Electronic signature". An "advanced electronic signature" is an electronic signature that meets some specific requirements set by the Directive.

The use of the open network has allowed more convenient financial services but has also made the nature of risks more complex (e.g. unauthorised access, illegal acquisition of PINs, theft of data, etc.).

\section{METHODOLOGY}

The methodology and process described here employs Usagecentred engineering for requirement engineering and analysis.

\subsection{Some of the Essential Use Cases}

$\begin{array}{ll}\text { Use Case: } & \text { Register Customer } \\ \text { Actors: } & \text { Customer } \\ \text { Purpose: } & \text { To obtain and store customer information } \\ & \text { for future reference. } \\ \text { Overview: } & \begin{array}{l}\text { The customer comes online and registers } \\ \text { either as a company or an individual in } \\ \text { case of a new member. }\end{array} \\ \text { Cross Reference: } & \text { Function R1.1 }\end{array}$

Use Case: Pay on Account

Actors: Customer

Purpose: To debit the account of customer on

$\begin{array}{ll} & \text { purchase of goods ordered. } \\ \text { Overview: } & \text { The customer makes payment for products }\end{array}$

Cross Reference: Function R3.1 bought by entering the account details.

\begin{tabular}{|c|c|}
\hline Use Case: & Pay on Card \\
\hline Actors: & Customer \\
\hline Purpose: & $\begin{array}{l}\text { To allow customers pay for the goods } \\
\text { ordered via a card. }\end{array}$ \\
\hline Overview: & $\begin{array}{l}\text { The customer makes payment for products } \\
\text { bought by entering the credit card details. }\end{array}$ \\
\hline \multicolumn{2}{|c|}{ Cross Reference: Function R3.2, R3.3 } \\
\hline Use Case: & Track My Order \\
\hline Actors: & Customer \\
\hline Purpose: & To examine the status of the order made. \\
\hline Overview: & $\begin{array}{l}\text { The customer takes an overall look of all } \\
\text { products bought and knows the state of } \\
\text { the order if it has been delivered or not. }\end{array}$ \\
\hline
\end{tabular}

Cross Reference: Function R2.2 


\subsection{Use - Case Model Diagram}
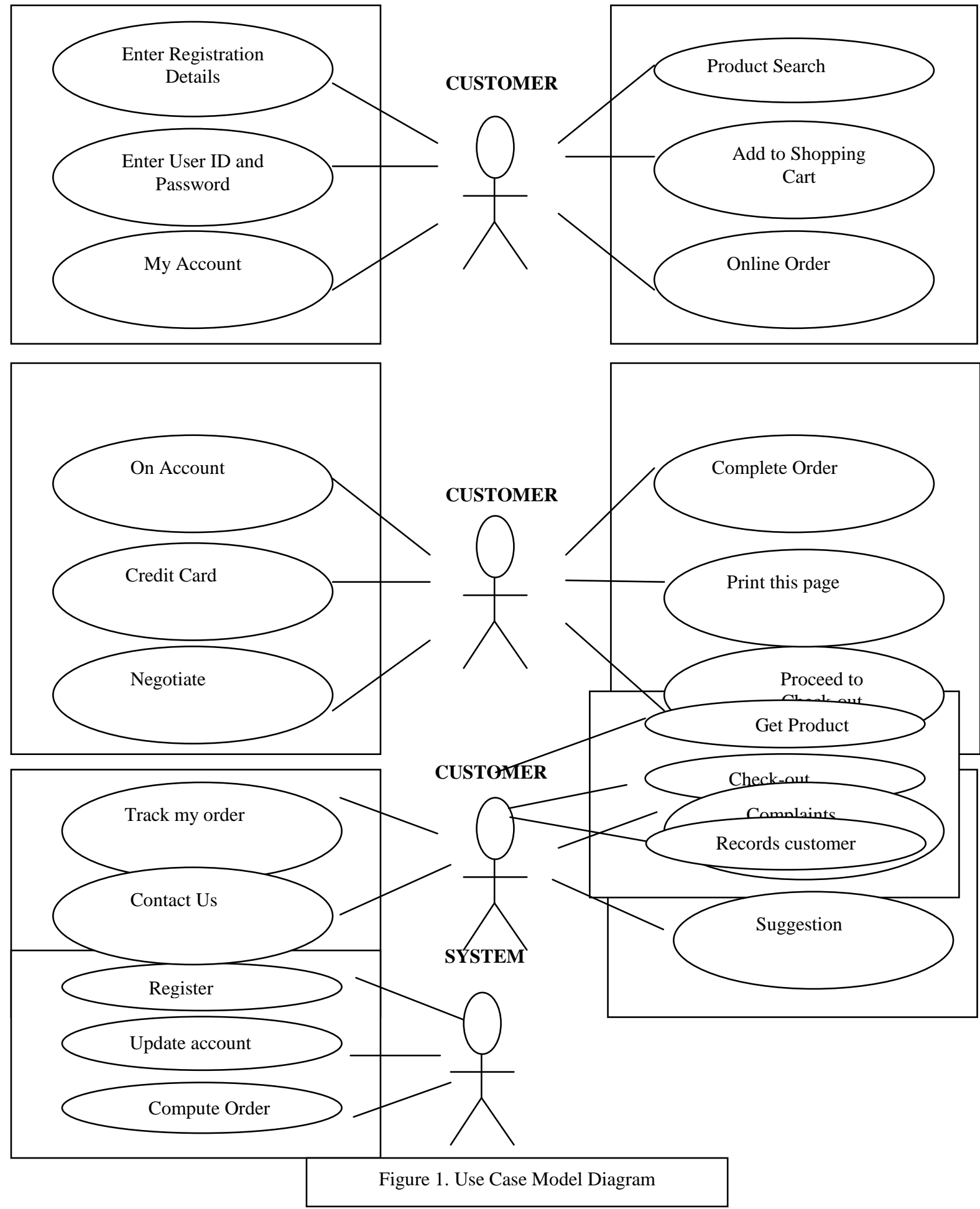


\subsection{System Function}

System functions are what a system is supposed to do. The tables below show the system functions for the proposed model.

Table 1. Basic functions of the e-commerce system

\begin{tabular}{|c|c|c|}
\hline $\begin{array}{l}\text { REFERENCE } \\
\text { NUMBER }\end{array}$ & FUNCTION & CATEGORY \\
\hline 1.1 & $\begin{array}{l}\text { Record the customer } \\
\text { details for future } \\
\text { reference. }\end{array}$ & Evident \\
\hline 1.2 & $\begin{array}{l}\text { Display information } \\
\text { of customer on } \\
\text { request. }\end{array}$ & Evident \\
\hline 1.3 & $\begin{array}{l}\text { Search for the } \\
\text { desired product by } \\
\text { the customer. }\end{array}$ & Evident \\
\hline 1.4 & $\begin{array}{l}\text { Display description } \\
\text { and price of item } \\
\text { recorded. }\end{array}$ & Evident \\
\hline 1.5 & $\begin{array}{l}\text { Provide a persistent } \\
\text { storage mechanism. }\end{array}$ & Hidden \\
\hline 1.6 & $\begin{array}{l}\text { Store completed } \\
\text { orders. }\end{array}$ & Hidden \\
\hline 1.7 & $\begin{array}{l}\text { Calculate current } \\
\text { sale total. }\end{array}$ & Evident \\
\hline 1.8 & $\begin{array}{l}\text { Increase order } \\
\text { inventory when } \\
\text { product is added to } \\
\text { shopping cart. }\end{array}$ & Hidden \\
\hline 1.9 & $\begin{array}{l}\text { Provide inter- } \\
\text { process and inter- } \\
\text { system } \\
\text { communication } \\
\text { mechanisms. } \\
\end{array}$ & Hidden \\
\hline 2.1 & $\begin{array}{l}\text { Customer must log } \\
\text { in with an ID and } \\
\text { password in order to } \\
\text { use the system. }\end{array}$ & Evident \\
\hline 2.2 & $\begin{array}{l}\text { Display product and } \\
\text { price of item } \\
\text { ordered. }\end{array}$ & Evident \\
\hline 2.3 & $\begin{array}{l}\text { Sends and receives } \\
\text { messages from the } \\
\text { forum. }\end{array}$ & Evident \\
\hline 2.4 & 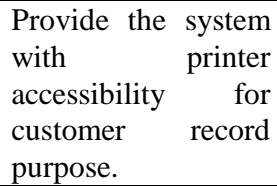 & Evident \\
\hline 2.5 & $\begin{array}{l}\text { The customer is } \\
\text { logged out. }\end{array}$ & Evident \\
\hline
\end{tabular}

Table 2. Payment functions of the e-commerce system

\begin{tabular}{|c|c|c|}
\hline $\begin{array}{l}\text { REFERENCE } \\
\text { NUMBER }\end{array}$ & FUNCTION & CATEGORY \\
\hline R3.1 & $\begin{array}{l}\text { Handle payments on } \\
\text { account, rapturing } \\
\text { amount paid and } \\
\text { calculating balance due. }\end{array}$ & Evident \\
\hline R3.2 & Handle credit payments, & \\
\hline
\end{tabular}

\begin{tabular}{|l|l|l|}
\hline & $\begin{array}{l}\text { via an internet based } \\
\text { credit authorization and a } \\
\text { secure server processing } \\
\text { of credit card } \\
\text { information. }\end{array}$ & \\
\hline R3.3 & $\begin{array}{l}\text { Log credit payments to } \\
\text { the accounts receivable } \\
\text { system, since the credit } \\
\text { authorization services } \\
\text { owes the store the } \\
\text { payment amount. }\end{array}$ & \\
\hline
\end{tabular}

\subsection{Conceptual Model}

A conceptual model illustrates abstract and meaningful concepts in the problem domain. The aim of this step is to decompose the problem in terms of individual concepts or objects [4].

The term domain covers the application area we are working with, i.e. E-Commerce.

$$
\text { Describes }
$$

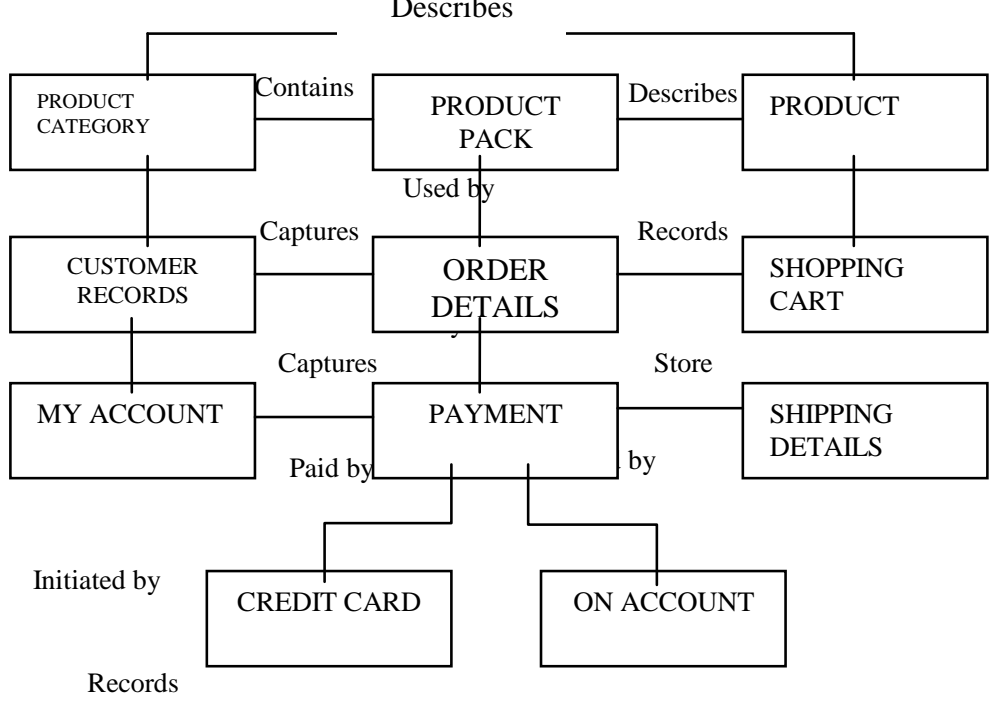

Figure 2. A conceptual model of e-commerce

\subsection{The Proposed System}

This system includes a 'shopping cart' feature which allows a product to be automatically added to an order. Customers can then receive on-line product availability and commitment.

Once the user has completed entering the order, including the desired billing, shipping, and payment information, the user reviews the order for completeness prior to its being added to open orders in the system.

\subsection{System Overview}

In this section we shall described how some components of the system are implemented due to lack of space.

\subsubsection{Registration Pages}

Every registered customer is given a user name and a password. They are expected to enter the site with his identification in other to load their personal settings and data. 


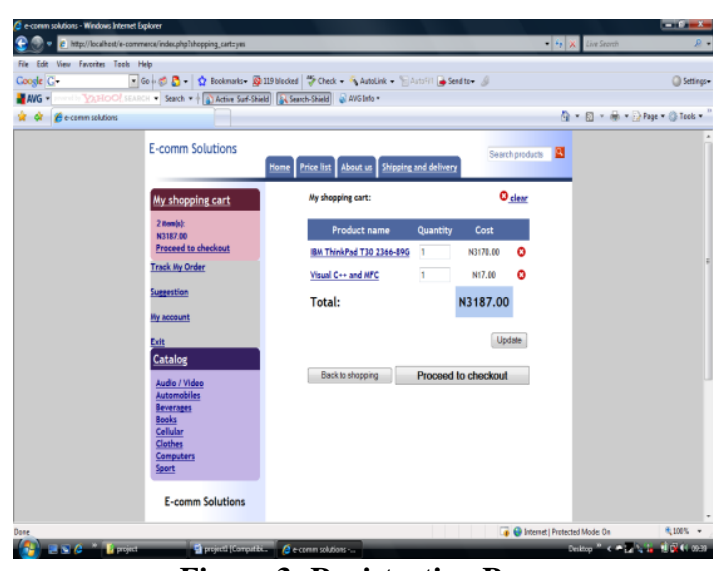

Figure 3: Registration Page

\subsubsection{Order Entry/Payment}

Payment for goods and services are done online by inputting their billing and shipping method.

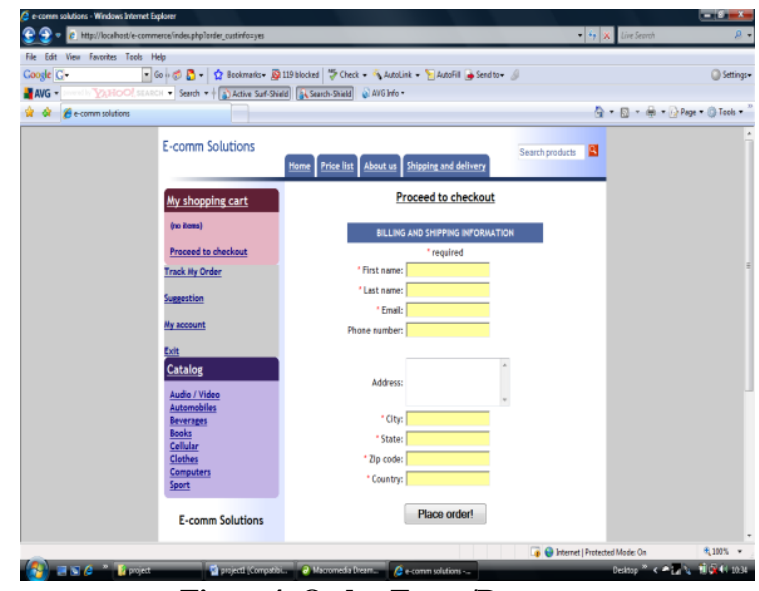

Figure4. Order Entry/Payment

\subsubsection{Order Completion Form}

This page shows that the order for goods had been made but yet to be paid for. The customer is then forwarded to the payment mode desired where payment is made.

\subsubsection{On Account}

During registration, certain pre-established rules where agreed upon between the user and the supplier. Customers may be willing to pay via their bank account with which they have a password for authentication.

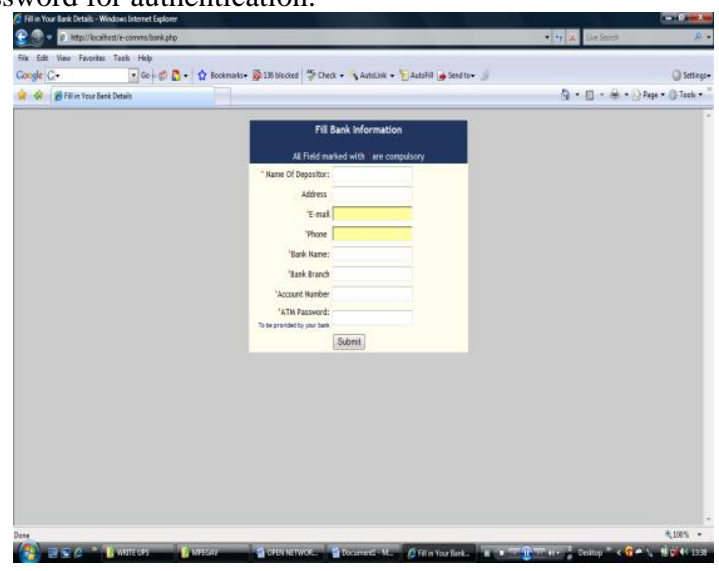

Figure 5. On Account Page

\subsubsection{Payment Authentication}

On submission of the account details and password, the customer is expected to enter the code forwarded to the Email address. This is for security resons because if the ATM password is stolen,it won't be easy to decipher the Email address and the password of the customer.

\section{DISCUSSIONS AND CONCLUSIONS}

\subsection{Discussions}

Open network systems, are rules-based e-payment systems that utilizes open, secure, global-settlement networks to process buyer-initiated payments. Open networks interface directly with front-end procurement and accounts payable systems to provide buyers and suppliers alike with a seamless, integrated corporate payment solution. Open networks also enable buyers to initiate and settle payments based on pre-established terms with suppliers.

Unlike enhanced p-card and ACH-based platforms, open networks employ a flexible fee schedule, allowing for the minimization of fees for relatively high-dollar amount transactions. In addition, open-network solutions may be easier to integrate with legacy environments. For example, Visa Commerce was designed to integrate with existing procurement applications, regardless of their sophistication. This integration strategy means that financial institutions, buyers, and suppliers that want to use an open network can do so with minimal upfront investment.

\subsection{Conclusions}

In this paper, we have described the implementation of a B2B E-commerce system for an online shopping cart. Requirements elicitation was carried out using Usage-centred engineering. A conceptual model is employed to help know the relationships between all the classes of the system, letting us know how they relate with one another.

Electronic signatures were employed for implementing security.

The system design is then translated into a computer code that functions properly with the end-user in mind. The implementation approach preserved and promoted harmonious communication between the users and developers. The following benefits are accrued:

$>$ A sophisticated product search capabilities product,

$>$ On-line order status tracking,

$>$ Online negotiation forum,

$>$ General as well as customer specific pricing

$>$ Flexible order entry pricing structure,

$>$ Secured payment method on bank account

$>$ Online order commitment,

$>$ Existing customer profile loaded at log-in,

$>$ Global exposure to the profile and activities of any company,

$>$ Unattended provision of company information to the whole world,

$>$ Fast and quick means of doing business,

$>$ Secured and efficient business operations. 


\section{REFERENCES}

[1]. Frederick T. Sheldon, et al., Case Study: B2B E-Commerce System Specification and Implementation Employing UseCase Diagrams, Digital Signatures and XML.

[2.]. Frank Martien. 2010 New Research on B2B Payments: Trends, Opportunities for Growth, and Strategies for Proactively Identifying Card Fraud and Misuse, Informatica, , webcast.

[3] Mark j. Cotteleer, Christopher a. Cotteleer, and Andrew Prochnow, Challenges and Choices in B2B E-payment. ACM journal (2007), 56-61.
[4]. Paola Masi (2002), The implementation of E-signatures in payment systems:: open issues and possible solutions, ECB CONFERENCE on E-payments in Europe.

[5]. Paul Walsh. 2010 The B2B Payment Problem. AFP Exchange, Vol. 21, No. 1. 32.

[6]. Zhiming Liu (2002). Object-Oriented Software Development with UML.

[7]. Steve Berez and Arpan Sheth. 2007 Break the Paper Jam in B2B Payments, Harvard Business Review 